\title{
New Clearance Evaluation Method for Hepatological Diagnostics
}

\author{
J. A. TICHÝ, M. LOUČKA ${ }^{1}$, Z. M. TREFNÝ, M. HOJEROVÁ, J. SVAČINKA, \\ J. MÜLLER ${ }^{1}$, M. FRIEDRICHOVÁ
}

Institute of Chemical Technology, Department of Mathematics, ${ }^{1}$ Institute of Civilization Diseases, Prague, Czech Republic

Received March 29, 2007

Accepted September 17, 2007

On-line October 11, 2007

\begin{abstract}
Summary
Pulse dye densitometry (PDD) enables the evaluation of hemodynamic state as well as liver function. A repeated examination, even after a short pause (or under stress condition), enables to follow safely the dynamics of liver pathology. From presented parameters we have evaluated as reliable the C5-clearance, an expression of equilibrium state in the two compartment liver system. Furthermore, T-index expresses ratio of $C 5$ value to cardiac output, it is a sensitive indicator of the blood pole, i.e. sinusoidal uptake, which is in very good correlation with staging of hepatopathies. The isolated $h$ constant in correlation to $T$-index is valuable For functional grading. The Japanese automatic analyzer of indocyanine green (ICG) dilution and elimination curves, after incorporation of a two compartment mathematical model, becomes more useful for complex hepatological diagnostics. Non-invasive PDD is becoming of uppermost importance to clinical interest, yielding comparable results as other complicated and invasive examinations and may be, therefore, repeated in short time intervals for different indications with minimal stress of examined patient.
\end{abstract}

\section{Key words}

Pharmacokinetics - Steatofibrosis hepatis (SFH) • Indocyanine green $\bullet$ Two-compartment model $\bullet$ Non-linear regression analysis - Clearance value $\bullet T$-index

\section{Corresponding author}

M. Loučka, Institute of Chemical Technology, Department of Mathematics, Technická 5, 16628 Prague 6, Czech Republic. E-mail: louckam@vscht.cz

\section{Introduction}

Non-invasive pulse dye densitometry (PDD) is becoming of uppermost importance to clinical interest, to comparable results from other complicated and invasive examinations (Haruna et al. 1998) and may be, therefore, repeated in short time intervals for different indications (Imai et al. 1998) with minimal stress of examined patient (Mitchell et al. 1995a, Su et al. 1999, Tichý and Loučka 2000).

The aim of this work was the analysis of dilution and elimination curves after single bolus injections of indocyanine green (ICG) (Iijima et al. 1998, Yang et al. 1972). We have focused our attention on the most sensitive clearance parameters for hepatological diagnostics (Shimizu et al. 1995, Su et al. 1999) and on the relationship between simultaneously determined hemodynamic and clearance values. Further, using our mathematical model (Komenda and Tichý 1965, Tichý and Komenda 1965, Tsukada et al. 1996) we have compared it with ICG kinetic analysis implemented in Japanese automatic PDD analyzer (NIHON-COHDEN).

\section{Methods}

PDD is carried out on bed-ridden patients with an empty stomach. Dilution and elimination curves describe the dependence of ICG concentration $\left(\mathrm{mg} / \mathrm{dm}^{3}\right)$ on time $(t)$. The state of circulation is usually simultaneously evaluated by bioimpedance measurement by using cardiodynamic data processing system (CDDPS) (Tichý 1995), with monitoring systemic blood pressure such as mean arterial pressure. Intravenous bolus in a dose $25-50 \mathrm{mg}$ (average $38 \mathrm{mg}$ ) was applied in less than 20 s. ICG concentration is monitored by nose or ear recorder (Mitchell et al. 1995b, Tichý and Loučka 2000) and determined values are compared with values estimated using direct photometry of at least two blood 
samples obtained during elimination phase in a precisely determined time.

Dilution curve is classically examined according to Hamilton (Tichý et al. 2005, Yang et al. 1972) and enables determination of cardiac output (CO) (Folkow and Neil 1971, Yang et al. 1972) or, in relation to body surface area, cardiac index $(C I)$. Correlation between hemodynamic parameters, determined by ICG dilution curves and by CDDPS is very satisfactory (Tsukada et al. 1996), however, in this work, it is not analyzed in detail. Appearance time $(A T)$ is time interval between bolus application and appearance of curves ascendant branch, expression of circulatory velocity (Yang et al. 1972).

(1)

$$
c(t)=\frac{g(t)}{\int_{0}^{\infty} g(t) d t}
$$

Dilution curve $c(t)$ is proportional to circulation concentration of tracer, further treated by numerical integration according to Simpson's rule. The integral corresponds to area under this curve.

$C O$ is determined from amount of given indicator $\left(I_{0}\right)$, average concentration $(m P)$ and mean transit time (MTT) (Folkow and Neil 1971)

(2)

$$
C O=\frac{I_{0}}{m P \cdot M T T} \cdot 60
$$

Dilution curves are monitored in one or two recirculatory peaks (Fig. 1). Pathological pattern of deformed curves in presence of intracardial shunts was not analyzed. Concentration signal may be, with satisfactory precision approximation, considered as rectangular pulse (Jaroš 1998, McBean and Rovers 1998).

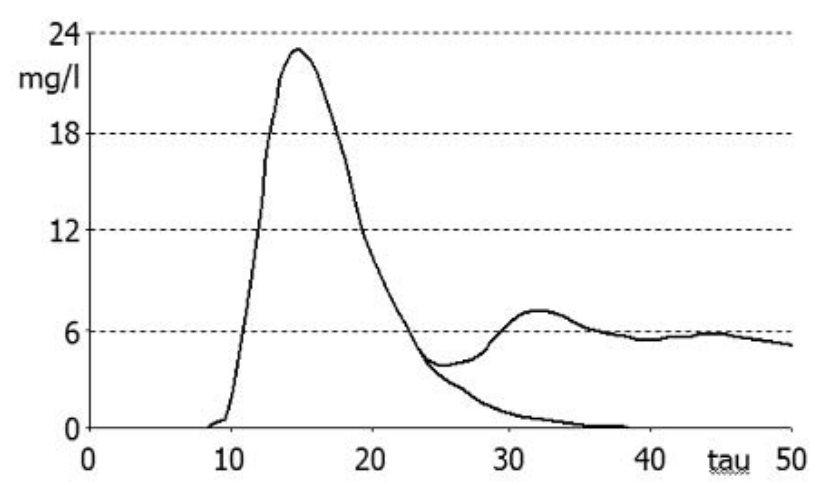

Fig. 1. Dilution curve.
Elimination curve (Fig. 2a) is given by gradual disappearance of ICG from blood, selectively through liver (Haruna et al. 1998, Iijima et al. 1998, Tichý and Loučka 2000). This process can be monitored from the 3 rd to 45 th min. The initial phase, after ICG application, may be analyzed by extrapolation or by calculation and virtual concentration $P(t)$ in time $t=0$ may be defined. The $P(0)$ in ratio to the given dose of ICG $\left(I_{0}\right)$ permits the calculation of $P V$ (plasma volume) or $B V$ (blood volume) (Iijima et al. 1998, Schad et al. 1987). In our examination the mean value of $P V$, in relation to body weight $55 \pm 11 \mathrm{ml} / \mathrm{kg}$, is considered to be physiological and is comparable with other determination methods (Haruna et al. 1998).

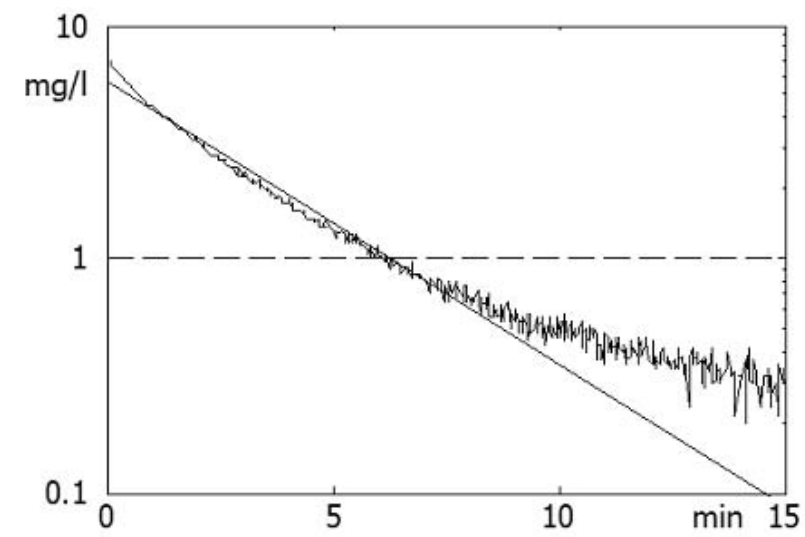

Fig. 2a. Elimination curve.

\section{Elimination curves analysis}

a) One parameter model:

The concept of a one-parameter model for ICG elimination is still being applied, including automatic analyzer NIHON-COHDEN. This issues from the differential equation describing the first order kinetics.

$$
\frac{d I(t)}{d t}=-k I(t)
$$

For initial condition $t=0, I(t)=I_{0}$ we obtain the following solution:

$$
\frac{I(t)}{I_{0}}=e^{-k t}
$$

assuming the complete distribution of given amount in 
plasma volume $(P V)$ in a concentration $P(0)$. The only diagnostic quantity is $k$ constant here.

\section{b) Two parameter model:}

The process between blood and liver (on sinusoidal membrane) and that between liver cells and bile (on canalicular membrane) are taken into account (Komenda and Tichý 1965, Tichý 1969). The agreement of digitalized curves (Fig. 2b) and their prediction, during utilization of a two parameter model, is very good (Tichý and Komenda 1965).

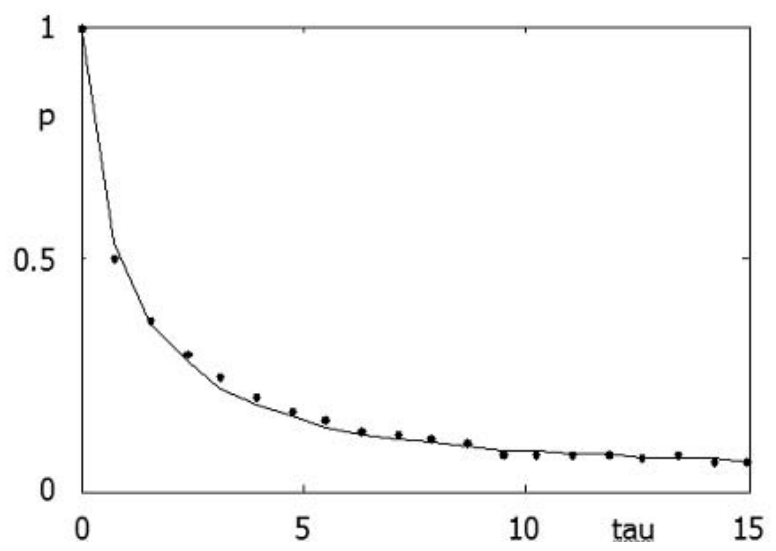

Fig. 2b. Digitalized elimination curve.

Differential equation, describing this proposed model (Tichý and Loučka 2000, Tichý et al. 2005), has the following form:

$$
\frac{d I(t)}{d t}=-k I(t)\left(1-\frac{I_{0}}{H_{0}}\right)-\frac{k}{H_{0}} I^{2}(t)
$$

Bernoulli equation of the second order is under consideration where for initial condition $t=0, I(t)=I_{0}$, it holds:

(6)

$$
\frac{I(t)}{I_{0}}=\frac{\left(1-\frac{I_{0}}{H_{0}}\right) e^{-k\left(1-\frac{I_{0}}{H_{0}}\right) t}}{1-\frac{I_{0}}{H_{0}} e^{-k\left(1-\frac{I_{0}}{H_{0}}\right) t}}
$$

When parameters are introduced it follows:

(7)

$$
h=\frac{H_{0}}{I_{0}}, \quad \varphi=k \frac{h-1}{h}
$$

then two parameter model is obtained in the following form:

$$
p(t)=\frac{I(t)}{I_{0}}=\frac{h-1}{h\left(e^{\varphi t}-1\right)}
$$

where parameters are evaluated by non-linear regression. It is the way how to obtain two independent characteristics $k$ and $h$ from data illustrated in Figure $2 \mathrm{~b}$ and to use whole part of curve for treatment.

Estimated values and indexes were statistically evaluated in relation to hepatological diagnosis, based on complex clinical and laboratory examination, including liver biopsy. This complex enables staging $(S)$ and grading $(G)$ of liver diseases (Lata et al. 2000, Ludwig 1995).

The clearance parameters according to following equations were calculated and their diagnostic sensibility was tested. For calculation of constants $k$ and $h$ the nonlinear regression according to formula (8) MarquardtLenvenberg algorithm was used. From individual values $k$ and $h$ constants the diagnostic clearance parameters were calculated according to the following equations (9) to (15):

$$
C_{2}=\frac{2 k I_{m}}{1-h+\sqrt{1+h^{2}}}
$$

$$
C_{3}=2 k I_{m}
$$

$$
C_{4}=\sqrt{2 k I_{m}}
$$

$$
\begin{aligned}
& C_{5}=\frac{k I_{m} h^{2} \ln h}{h^{2}-1}=\frac{2 C_{1} C_{6}}{C_{3}} \\
& C_{6}=k I_{m} \frac{h}{h+1}=C_{3} \frac{h}{2(h+1)}
\end{aligned}
$$

$$
T=\frac{C 5}{C O}
$$


Subjects

The studied groups consisted from 31 males and 3 females (average age 55.4 years; range 20-79 years). Four patients were first examined while lying down and for the second time with equivalent ICG dose under continual stress of 60 to $70 \mathrm{~W}$ in unchanged bed-ridden position for a period of $30 \mathrm{~min}$.

Group 0) Physiological liver, without evidence of liver disease $(n=6)$.

Group 1) Damage of liver (non-cirrhotic) was defined by different degree of steatosis, fibrotization of periportal fields, eventually by portoportal septal formation. Different cellularization in portobilliar fields and alteration of lobular structure (alcoholic $n=12$ and non-alcoholic $n=11$ ) were found. This concerns mainly patients with metabolic syndromes of diabetes type II, with insulin resistance, disorder of lipid metabolism, gout and morbid obesity (BMI $\geq 40)(n=23)$.

Group 2) Cirrhotic liver with evolution of portal hypertension was classified according to Child-Pugh's score (Ludwig 1995) in group A, B, and C $(n=5)$.

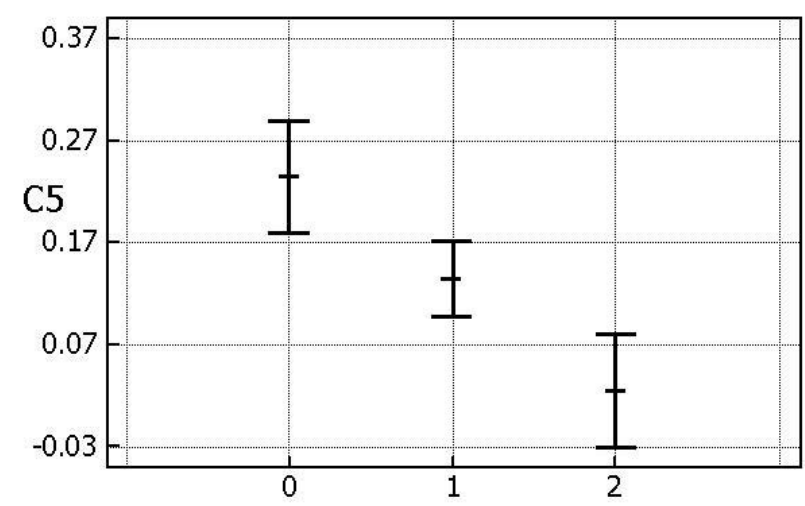

Fig. 3. $95 \%$ confidence intervals of $\mathrm{C} 5$.

The activity of hepatocellular damage was evaluated and was taken into account with type and size of parenchymal cells necrosis in grading, including the laboratory findings, especially aminotransferase levels and hepatitis markers. Analysis of variance (Jaroš 1998), namely one-way ANOVA and Kruskall-Wallis test (McBean and Rovers 1998), was used for statistical treatment. The same method was used for the statistical evaluation of the complex clinical state worth of all determined clearance parameters (see eqs. (9) to (15)). The proper C5 value (equation (13)) has a great differential diagnostic ability, as follows from (Fig. 3) and is statistically defined by $95 \%$ confidence interval.

All given confidence intervals of mean values are disjunctive, differing three groups of hepatopathies presented above. The quantity $k$ calculated from model represented by eq. (4) is not able to differentiate reliably these three groups of hepatopathies (Fig. 4).

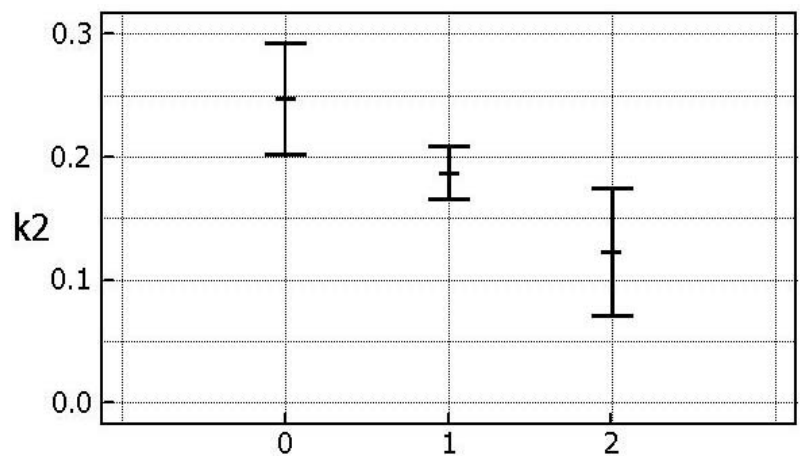

Fig. 4. $95 \%$ confidence intervals for $k_{2}$ value.

$T$-index eq. (15) is also considered to be clinically very important because it reliably distinguishes this relatively heterogeneous non-cirrhotic group from cirrhotic patients, mainly A type (four-times) and C type (once).

The discrimination ability of $T$-index is also apparent during evaluation of the group (0), without conclusive hepatopathy (bioptically not verified), as compared to alcoholic and non-alcoholic steatosis/ steatofibrosis (group 1) (mostly bioptically verified) as it is shown in Figure 5.

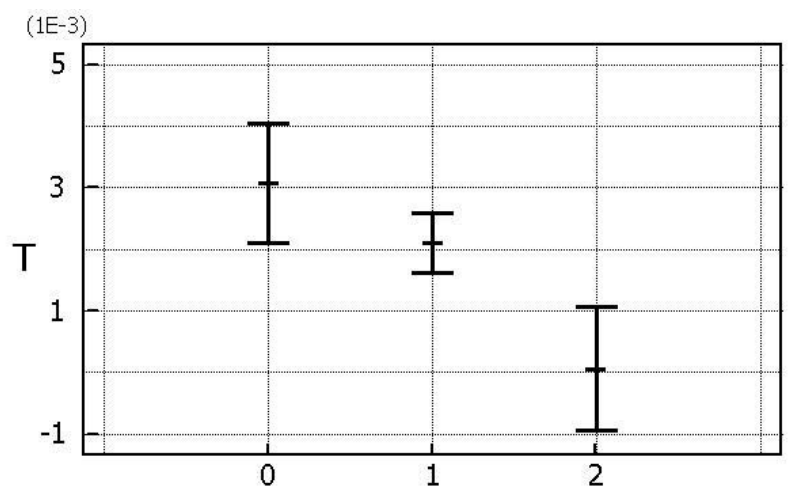

Fig. 5. $95 \%$ confidence intervals for $T$ value.

Table 1. $C 5$ boundaries determined for classification.

\begin{tabular}{lcc}
\hline $\begin{array}{l}\text { Clinical } \\
\text { diagnosis }\end{array}$ & $\begin{array}{c}\text { Assignment } \\
\text { in Figure }\end{array}$ & $\begin{array}{c}\text { C5 confidence } \\
\text { intervals 95 \% }\end{array}$ \\
\hline $\begin{array}{l}\text { Healthy } \\
\text { Steatosis }\end{array}$ & 0 & $<0.17989 ; 0.29189>$ \\
$\begin{array}{l}\text { and/or fibrosis } \\
\text { Cirrhosis }\end{array}$ & 1 & $<0.11192 ; 0.17041>$ \\
\end{tabular}




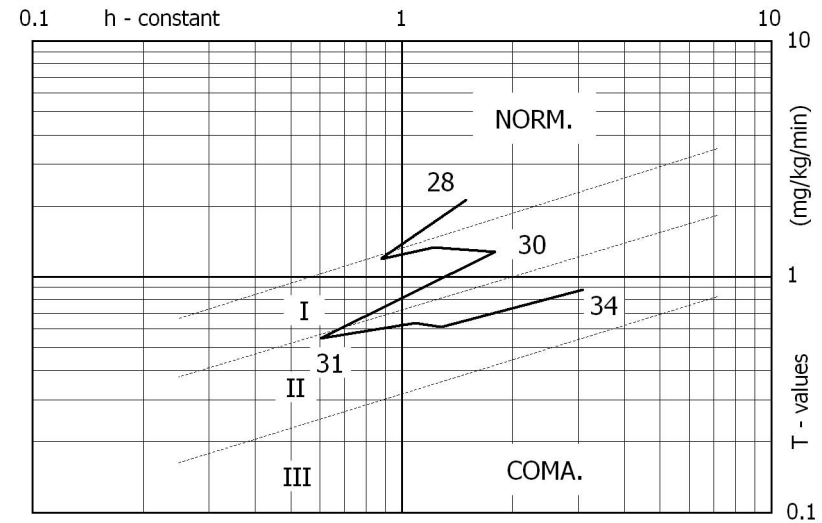

Fig. 6. The relationship of isolated h constant to $C 5$ or $T$-values. $28,30,31,34$ indicate the age of patient, I, II, III represent the degrees according to Child classification.

\section{Results and Discussion}

Priority is given to ICG clearance before the previously widely used bromsulphoftalein (BSP) (Komenda and Tichý 1965, Tichý and Komenda 1965), because ICG does not cause anaphylactic or other allergic reactions. Unfortunately, the availability of ICG is limited in our country. The more complex is the physiopathological knowledge of pharmacokinetics of used indicators, the richer is the clinical experience, the more increases its diagnostic worth. ICG, but also BSP (when used for many years), enables to determine liver damage, its severity even though it has different etiology (Lata et al. 2000). This was interpreted as functional blood pool failure of liver (on sinusoidal membrane), in close relation to staging of liver diseases. For the activity evaluation, i.e. grading, the correlation with presented clearance and $T$-index parameters is of low significance. For grading (functional state of canalicular membrane) is better expressed by isolated $h$ constant in relation to $C 5$ or $T$-values (Fig. 6).

\section{List of symbols}

$C$ clearance values $\left[6.10^{-5} \cdot \mathrm{s}^{-1}, 6 \mathrm{kmol} \cdot \mathrm{kg}^{-1} \cdot \mathrm{s}^{-1}\right]$

$h \quad$ relative liver capacity [1]

$H(t)$ amount of tracer in the liver space [mmol], [mg]

$H_{0} \quad$ absolute liver capacity $\quad[\mathrm{mmol}],[\mathrm{mg}]$

$I(t) \quad$ rest amount in blood $\quad[\mathrm{mmol}],[\mathrm{mg}]$

$I_{0} \quad$ given dose of indicator $\quad[\mathrm{mmol}],[\mathrm{mg}]$

$I_{m} \quad$ given dose related to body weight

$\begin{array}{ll} & {[\mathrm{mmol} / \mathrm{kg},} \\ & \text { relative elimination rate } \\ {\left[(60 . \mathrm{s})^{-1}\right]}\end{array}$

$p(t) \quad$ relative plasma concentration

$t$ time [60.s]

$P V \quad$ plasmatic volume $\quad[\mathrm{ml}]$

$\mathrm{CO}$ cardiac volume $\quad\left[\mathrm{ml} . \mathrm{s}^{-1}\right]$

$T \quad$ index [1]

C5 clearance $\quad\left[6.10^{-5} \cdot \mathrm{s}^{-1}, 6 \mathrm{kmol} \cdot \mathrm{kg}^{-1} \cdot \mathrm{s}^{-1}\right]$

\section{Conflict of Interest}

There is no conflict of interest.

\section{Acknowledgements}

This work was supported through the Research Grant of Ministry of Education, Youth and Sports of the Czech Republic (research program MSM6046137307).

\section{References}

FOLKOW B, NEIL E: Circulation. Oxford University Press, London, 1971.

HARUNA M, KUMON K, YAHAGI N, WATANABE Y, ISHIDA Y, KOBAYASHI N, AOYAGI T: Blood volume measurement at the bedside using ICG pulse spectrophotometry. Anestesiology 89: 1322-1328, 1998.

IIJIMA T, IWAO Y, SANKAWA H: Circulating blood volume measured by pulse dye-densitometry: comparison with 131 I-HSA analysis. Anestesiology 89: 1329-1335, 1998.

IMAI T, TAKAHASHI K, GOTO F, MORISHITA Y: Measurement of blood concentration of indocyanine green by pulse dye densitometry. Comparison with the conventional spectrophotometric method. J Clin Monit Comput 14: 477-484, 1998.

JAROŠ F: Probability and Statistics. (in Czech) VŠCHT, Prague, 1998.

KOMENDA S, TICHÝ JA: Mathematical modeling of bromsulphoftalein (BSP) kinetics (in Czech). Čs fysiol 14: 281283, 1965.

KOSCHIN F, KÁRNÍK I, MAREK L, ET AL.: Statgraphic or Statistics for Everybody. (in Czech) Grada, Prague, 1992.

LATA J, DÍTĚ P, HŮLEK P, KRAJINA A, KRÁL V, ŠAFKA V: Portal Hypertension in Liver Cirrhosis. (in Czech), GAAN CZ, Plzeň, 2000. 
LUDWIG J: Histopathological diagnosis and terminology of chronic hepatitis. J Hepatol 23 (Suppl): 49-53, 1995.

MCBEAN EA, ROVERS FA: Statistical Procedures for Analysis of Environmental Monitoring Data and Risk Assessment. Prentice Hall PTR, Upper Saddle River, NJ, 1998.

MITCHELL IM, POLLOCK JC, JAMIESON MP: The validation of auricular densitometry for indocyanine green clearance measurement of hepatic blood flow during and after cardiopulmonary bypass in children. Perfusion 10: $197-208,1995 \mathrm{a}$.

MITCHELL IM, POLLOCK JC, JAMIESON MP: Effects of dopamine on liver blood flow in children with congenital heart disease. Ann Thorac Surg 60: 1741-1744, 1995b.

SCHAD H, HAIDER M, BRECHTELSBAUER H: Bestimmung des Plasmavolumens mit Indocyaningrün. Anesthesist 36: 608-614, 1987.

SHIMIZU S, KAMIIKE W, HATANAKA N: New method for measuring ICG $\mathrm{R}_{\max }$ with a clearance meter. World J Surg 19: 113-118, 1995.

SU MY, LIN DY, SHEEN IS, CHU CM, CHIU CT, LIAW YF: Indocyanine green clearance test in non-cirrhotic hepatitis patients: a comparison an analysis between convention blood sampling method and finger piece monitoring method. Changgeng Yi Xue Za Zhi 22: 17-24, 1999.

TICHÝ JA: The double retention test. Mod Gastroenterol 1: 1461-1462, 1969.

TICHÝ JA: Juvenile type of arterial hypertension in aging. (in Czech) Med Sport Bohemo-Slov 4: 113-115, 1995.

TICHÝ JA, KOMENDA S: Bromsulphoftalein tests: the use of a new method of hepatic clearance after single bromsulphoftalein injection. (in Czech) Vnitř lék 11: 625-637, 1965.

TICHÝ JA, LOUČKA M: Non-invasive measurement of hemodynamics and hepatic clearance by indocyanine green (ICG) in hepatology. Abstr Int Congr Hemodynamics, Čejkovice, 2000.

TICHÝ JA, LOUČKA M, TREFNÝ ZM: The new clearance method for hepatic diagnostics. Prague Med Rep 106: 229-242, 2005.

TSUKADA K, SAKAGUCHI T, AONO T, ISHIZUKA D, FUJITA N, HATAKEYAMA K: Indocyanine green disappearance enhanced by prostaglandin $\mathrm{E}_{1}$ in patients with hepatic resection. $J$ Surg Res 66: 64-68, 1996.

YANG SS, MARANHAO V, BENTIVOLGIO LG, GOLDBERG H: From Cardiac Catheterization Data to Hemodynamic Parameters. F.A. Davis, Philadelphia, 1972. 